\title{
Emerging Evidence for Cannabis' Role in Opioid Use Disorder
}

\author{
Beth Wiese ${ }^{1,2}$ and Adrianne R. Wilson-Poe ${ }^{2, *}$
}

\begin{abstract}
Introduction: The opioid epidemic has become an immense problem in North America, and despite decades of research on the most effective means to treat opioid use disorder (OUD), overdose deaths are at an all-time high, and relapse remains pervasive.

Discussion: Although there are a number of FDA-approved opioid replacement therapies and maintenance medications to help ease the severity of opioid withdrawal symptoms and aid in relapse prevention, these medications are not risk free nor are they successful for all patients. Furthermore, there are legal and logistical bottlenecks to obtaining traditional opioid replacement therapies such as methadone or buprenorphine, and the demand for these services far outweighs the supply and access. To fill the gap between efficacious OUD treatments and the widespread prevalence of misuse, relapse, and overdose, the development of novel, alternative, or adjunct OUD treatment therapies is highly warranted. In this article, we review emerging evidence that suggests that cannabis may play a role in ameliorating the impact of OUD. Herein, we highlight knowledge gaps and discuss cannabis' potential to prevent opioid misuse (as an analgesic alternative), alleviate opioid withdrawal symptoms, and decrease the likelihood of relapse.

Conclusion: The compelling nature of these data and the relative safety profile of cannabis warrant further exploration of cannabis as an adjunct or alternative treatment for OUD.
\end{abstract}

Keywords: cannabis; opioid addiction; opioid treatment; relapse prevention

\section{Introduction}

The opioid epidemic has become an increasingly pressing problem with an estimated $26-36$ million people abusing opioids around the world. ${ }^{1}$ At the time of this publication, the Centers for Disease Control reports that 115 people die every day of an opioid related cause in the United States, and more than 33,000 people lost their lives to an accidental opioid overdose in the United States in 2015 alone. ${ }^{1-4}$ The United States consumes $80 \%$ of the world's supply of prescription opioid analgesics (POAs), and opioid prescriptions have climbed by $300 \%$ since $1991 .^{5}$ The rise in opioid prescriptions has also widened the demographic of individ- uals dying from opioid overdose; historically, overdose was most prevalent in urban, minority adolescent males; however, today these lethal effects are similar across race, gender, socioeconomic status, and geography. ${ }^{7-11}$ The spike in prescriptions has also directly contributed to an increase in the number of first-time consumers of illicit opioids (heroin, which is commonly laced with fentanyl or its analogs), which has continued to climb since the mid 1990's. ${ }^{6}$ Patients who become physically dependent upon POAs frequently switch to illicit opioids because POAs are more costly and/or difficult to obtain. ${ }^{3,8,12,13}$ However, ease of access is a dangerous tradeoff for the lethal risk that is associated

\footnotetext{
${ }^{1}$ Department of Psychology, University of Missouri-St. Louis, St. Louis, Missouri.

${ }^{2}$ Department of Anesthesiology, Pain Center, Washington University School of Medicine, St. Louis, Missouri.

*Address correspondence to: Adrianne R. Wilson-Poe, MA, Department of Anesthesiology, Pain Center, Washington University School of Medicine, 660 South Euclid Avenue, Campus Box 8054, St. Louis, MO 63110, E-mail: poea@anest.wustl.edu

(c) Beth Wiese and Adrianne R. Wilson-Poe 2018; Published by Mary Ann Liebert, Inc. This Open Access article is distributed under the terms of the Creative Commons License (http://creativecommons.org/licenses/by/4.0), which permits unrestricted use, distribution, and reproduction in any medium, provided the original work is properly cited.
} 
with synthetic opioids. Fentanyl, for instance, is 100 times more potent than morphine, which partially explains why there was a $250 \%$ increase in synthetic opioid mortality between 2012 and $2015 .^{14,15}$

This unprecedented public health crisis warrants the investigation of novel sustainable interventions which would directly address the current opioid misuse crisis, complement current treatment strategies, and prevent future misuse through alternative first line analgesics.

\section{Mechanistic Interactions between \\ Cannabis and Opioids}

The endocannabinoid and opioidergic systems are known to interact in many different ways, from the distribution of their receptors to cross-sensitization of their behavioral pharmacology. Cannabinoid-1 (CB1) receptors and mu opioid receptors (MORs) are distributed in many of the same areas in the brain, including but not limited to the periaqueductal gray, ${ }^{16,17}$ locus coeruleus, ${ }^{18,19}$ ventral tegmental area (VTA), nucleus accumbens, prefrontal cortex (PFC) ${ }^{20}$ central amygdala (CeA), bed nucleus of stria terminalis (BNST), ${ }^{21}$ caudate putamen (CP), substantia nigra, dorsal hippocampus, raphe nuclei, and medial basal hypothalamus. ${ }^{22}$ The extent of this overlapping expression and frequent colocalization of the CB1 and MOR provide clear morphological underpinnings for interactions between the opioid and cannabinoid systems in reward and withdrawal. ${ }^{19,23}$

There is a bidirectional relationship between MORs and $\mathrm{CB} 1$ receptors in the rewarding properties of drugs of misuse. ${ }^{20,24-28}$ That is, modulation of the CB1 receptor has profound effects on the rewarding properties of opioids, and vice versa. For example, MOR and CB1 receptors are reciprocally involved in the development of drug-induced conditioned place preference (CPP). Coadministration of a cannabinoid antagonist and morphine attenuates the development of morphine $\mathrm{CPP},{ }^{26}$ and coadministration of an opioid antagonist blocks tetrahydrocannabinol (THC)-induced CPP. ${ }^{25}$ Interestingly, microinjections of $\mathrm{CB} 1$ agonists into the medial PFC creates an aversion to doses of morphine that are normally rewarding (CPP), while CB1 antagonism in this brain region creates a rewarding effect of subthreshold morphine doses. ${ }^{24}$ In addition, administration of cannabinoids to MOR knockout (KO) mice produces a weaker CPP compared to wild-type animals, ${ }^{22}$ reviewed in Wills and Parker. ${ }^{27}$ This mutual involvement in reward is at least partially mediated by presynaptic cannabinoid and opioid disinhibition of dopamine neurons in the VTA, a well-characterized mechanism in the rewarding properties of drugs of misuse. ${ }^{20}$ Although these mechanisms have not been well studied in humans, one study has found CB1 upregulation in the reward pathway of individuals who use opioids, which supports a role for the endocannabinoid system in the development of opioid misuse. ${ }^{29}$

There is abundant support for the role of $\mathrm{CB} 1$ receptors in the rewarding effects of opioids and the amelioration of tolerance. However, the effects of endogenous and exogenous cannabinoids in opioid withdrawal are somewhat paradoxical: endogenous cannabinoids seem to have no role in somatic withdrawal, ${ }^{27,30-32}$ yet exogenous CB1 agonists readily alleviate somatic symptoms such as escape jumps, diarrhea, weight loss, and paw tremors. ${ }^{28,33,34}$ Endogenous cannabinoid tone within the amygdala is also involved in the affective component of opioid withdrawal, as blockade of CB1 receptors in the CeA or BNST ameliorates opioid withdrawal. ${ }^{21}$ The kappa opioid receptor (KOR) system may also play a role in cannabis' impact on the affective opioid withdrawal, given its pivotal contributions to dysphoria and negative effect. ${ }^{35}$ However, both KOR agonism (with $\mathrm{U} 50,488 \mathrm{H}^{30}$ ) and KOR antagonism (naloxone ${ }^{31,32}$ ) have both been shown to attenuate conditioned place aversion in CB1 KO mice. ${ }^{30}$ These contradicting data highlight the need for additional mechanistic insights into the involvement of the $\mathrm{CB} 1$ receptor in opioid reward and withdrawal.

\section{Cannabis as a First Line Analgesic}

The primary use for both prescription opioids and cannabis is for analgesia. Currently, up to $90 \%$ of patients in state-level medical cannabis registries list chronic pain as their qualifying condition for the medical program. ${ }^{36}$ In an exhaustive review, the National Academies of Science and Medicine recently confirmed the efficacy of cannabis for chronic pain in adults. ${ }^{36}$ Interestingly, when given access to cannabis, individuals currently using opioids for chronic pain decrease their use of opioids by $40-60 \%$ and report that they prefer cannabis to opioids. ${ }^{37-42}$ Patients in these studies reported fewer side effects with cannabis than with their opioid medications (including a paradoxical improvement in cognitive function) and a better quality of life with cannabis use, compared to opioids. Despite the vast array of cannabis products and administration routes used by patients in states with medical cannabis laws, cannabis has been consistently shown to reduce the opioid dose needed to achieve desirable pain relief. ${ }^{41,43}$

One of the mechanisms that may explain the opioid sparing effects of cannabis is its ability to produce 
synergistic analgesia. ${ }^{44-46}$ In humans, subanalgesic doses of THC and morphine are equally unsuccessful at reducing the sensory or affective components of pain; however, when the same doses of THC and morphine are coadministered, they produce a significant reduction in the affective component of pain. ${ }^{47}$ These synergistic effects are also observed when patients using opioids for pain vaporize whole-plant cannabis, as opposed to experimentally administered isolated THC. ${ }^{48}$ Adjunct whole plant cannabis has no effect on the pharmacokinetics of opioids, which further supports a synergistic mechanism behind the opioid sparing and enhanced analgesia produced by cannabis. ${ }^{48}$ Furthermore, in pre-clinical models, coadministration of opioids and cannabinoids attenuates the development of opioid tolerance. ${ }^{49,50}$

Combined, these clinical and pre-clinical data suggest that analgesic synergy produced by coadministered cannabis and opioids could be harnessed to achieve clinically relevant pain relief at doses that would normally be subanalgesic. This strategy could have significant impacts on the opioid epidemic, given that it could entirely prevent two of the hallmarks of opioid misuse: dose escalation and physical dependence.

Because patients report substituting cannabis for several types of pharmaceutical drugs, including opioids, benzodiazepines, and antidepressants, ${ }^{51}$ analgesic synergy may not entirely explain the opioid-sparing effects of cannabis in pain patients. Economic and lifestyle considerations may also play a pivotal role in opioid sparing and substitution. Patients report that their reasons for substituting cannabis for other medications include less severe side effects, less withdrawal potential, ease of access, and better symptom management for their conditions. ${ }^{52}$

Although there is insufficient clinical literature to support the use of cannabis as a treatment for acute pain, there is a long-standing body of pre-clinical evidence that demonstrates the antinociceptive effects of cannabinoids in pain-free, drug-naive animals. ${ }^{17,49,53-57}$ The mechanisms of cannabinoid antinociception are remarkably similar to those of opioid analgesics. Both the $\mathrm{CB} 1$ and MOR are G-protein coupled receptors, and agonist-initiated disinhibition of GABA release in the descending pain pathway is just one example of overlapping antinociceptive mechanisms between these drugs. ${ }^{17,23,58-62}$ Evidence supporting the role of cannabis in acute, nonsevere pain management could lead to a substantial reduction in opioid prescription rates, thereby eliminating patient exposure to the risks of opioid dose escalation and physical dependence. This criti- cal gap in the clinical literature and potential clinical impacts of this therapy warrants further exploration of the efficacy of cannabis for acute pain relief.

\section{Current Opioid Use Disorder Therapies and Their Shortcomings}

The most prominent and pervasive problem in opioid use disorder (OUD) treatment is the prevention of drug relapse, which is extremely common during acute withdrawal (detoxification), as well as during protracted recovery after physical withdrawal symptoms have subsided. ${ }^{63-66}$ Abstinence-based protocols are particularly ineffective, as $85 \%$ of individuals relapse within 12 months of the initiation of treatment. ${ }^{65}$ In-patient residential treatment facilities do not appear to improve abstinence-based therapy, as relapse rates in this paradigm are as high as $80 \%$, when measured 2 years after treatment initiation. ${ }^{67}$ Compared to abstinence, opioid replacement and medication-assisted therapies, which began in the 1960s, are more efficacious for relapse prevention; however, there are currently only four FDA-approved medications for the treatment of OUD. ${ }^{68-71}$ Off-label prescription medications such as benzodiazepines and antiemetics are also common, but these therapies are largely directed at symptom management during acute detoxification rather than relapse prevention. ${ }^{72}$ In this review, we focus on the most widely used OUD therapies, their shortcomings, and the bottlenecks to accessing them. ${ }^{11}$

Methadone, a full MOR agonist, was approved by the FDA in 1974 to aid in opioid cessation., ${ }^{9,73}$ Individuals enrolled in consistent dose methadone maintenance programs are more likely to stop using nonprescribed opioids than individuals not enrolled in the maintenance program. ${ }^{74}$ Although methadone has an encouraging safety profile, ${ }^{75}$ it carries some risk for misuse and mortality when the dose exceeds the patient's level of tolerance. ${ }^{76,77}$ Withdrawal symptoms from methadone mimic those of other opioids when stopped abruptly or tapered too quickly, and these symptoms last up to 3 weeks longer than withdrawal from other opioids. ${ }^{9,78,79}$ There are only 1590 methadone distributers in the United States, which are highly regulated clinics that are concentrated in urban areas, creating geographical disparities in OUD treatment. ${ }^{10,11,79}$ In addition to geographical barriers, these clinics frequently have stringent and stigmatizing compliance requirements, such as daily visits and frequent urine screenings for illicit drugs. ${ }^{11,80}$ Although these barriers to treatment could potentially be addressed 
through concerted efforts to expand access, $40 \%$ of patients still relapse within 1 year of initiating methadone therapy. ${ }^{67}$

Buprenorphine (Subutex) is a partial MOR agonist and KOR antagonist that can reduce withdrawal symptoms, cravings, and additional opioid use. ${ }^{76,81,82}$ The inclusion of naloxone in some buprenorphine formulations (Suboxone, Zubsolv) is intended to reduce misuse by precipitating withdrawal when it is used intravenously, ${ }^{82,83}$ and despite the presence of naloxone, there is still some risk for misuse and overdose. ${ }^{77,83,84}$ The inclusion of naloxone can also induce withdrawal when administered too soon after the most recent dose of other opioids. ${ }^{63,67,85}$

Unlike methadone, Suboxone offers a primary care approach to medication-assisted therapy, as it can be dispensed by a pharmacy rather than a specialized clinic. ${ }^{86,87}$ However, only $3 \%$ of physicians possess the additional Drug Enforcement Agency credentials required to prescribe buprenorphine, ${ }^{76,88}$ and there are strict limits on the number of patients they are permitted to serve. ${ }^{89}$ Buprenorphine-licensed physicians also tend to be concentrated in larger cities, leaving $46.8 \%$ of counties in the United States, especially rural areas and the Midwest, with a shortage in convenient access to these treatment options. ${ }^{88,90,91}$ While long-term treatment retention with buprenorphine or Suboxone is not as well characterized as methadone, a Swedish study has shown retention rates of up to $75 \%$ following a year of buprenorphine/ Suboxone treatment. ${ }^{92}$ However, a 24 -week clinical trial in the United States reveals that buprenorphine retention is only $46 \% .^{93}$

Evidence suggests that the most effective tool for relapse prevention is medication-assisted pharmacotherapy, combined with social support. ${ }^{76,78,94,95}$ Because of the overwhelming evidence that supports this concurrent treatment model, there is little rationale to deviate from this approach. However, expanded access to these therapies is highly warranted, as are novel and alternative therapies which improve efficacy, diminish geographical disparities, and eliminate the need for specialty physicians. ${ }^{96}$

\section{Cannabis During Acute Opioid Withdrawal}

The first barrier to overcoming OUD is getting patients through the acute withdrawal period, or detoxification. Although pharmacotherapies such as methadone and buprenorphine are largely successful and widely utilized for this purpose, there are shortcomings to this approach, which are highlighted above. ${ }^{9,76,78,80,82,83,87,89-91,97}$ In May of 2018, the FDA approved the use of lofexidine, an alpha-2 adrenergic receptor agonist for acute (14 day) opioid withdrawal. Lofexidine provides substantially more symptom relief than placebo; however, the comparative efficacy of lofexidine in combination with long-acting opioid agonists or opioid antagonists is still being characterized. ${ }^{71,98-100}$

There is also nascent evidence that suggests that cannabis may be an efficacious tool during the acute opioid withdrawal period. Numerous pre-clinical studies have shown that cannabis and cannabinoids decrease opioid withdrawal symptoms. ${ }^{6,33,34,97,101-103}$ Although this evidence supports the use of cannabinoids as a possible treatment in OUD treatment, ${ }^{28}$ conflicting evidence demonstrates that CB1 agonism increases the rewarding properties of opioids ${ }^{22,102}$ and may actually increase the severity of opioid withdrawal symptoms. ${ }^{18,104}$ These conflicting data highlight the need for a mechanistic characterization of CB1 agonism as a therapeutic target for opioid withdrawal, a need that is further substantiated by the pharmacology of CB1 antagonism. For instance, some studies show that acute administration of SR-141716A, a CB1 antagonist, can reduce opioid withdrawal; however, this effect is profoundly affected by the experimental conditions. ${ }^{22,105}$ Because this effect can be recapitulated in $\mathrm{CB} 1 \mathrm{KO}$ mice, $\mathrm{CB} 1$ antagonism only partially mediates these effects. ${ }^{102}$ To complicate the story further, the administration of cannabidiol (CBD), a very promiscuous phytocannabinoid with at least a dozen mechanisms of action, also alleviates naloxoneprecipitated withdrawal in morphine tolerant rats. ${ }^{106-112}$

Although the mechanisms by which cannabinoids alleviate opioid withdrawal are complex and unclear, some reports suggest that cannabis may alleviate opioid withdrawal in humans. ${ }^{18,113}$ For instance, patients engaging in medication-assisted detoxification from opioids reported using cannabis when opioid maintenance doses were not high enough to prevent withdrawal and cravings. ${ }^{114}$ However, some individuals reported that cannabis was often ineffective and sometimes worsened overall severity of the withdrawal symptoms. Because the phytochemical makeup and cannabinoid content of cannabis have a significant effect on subjective human experiences, ${ }^{115}$ it is plausible that these variable experiences are the result of variable phytochemistry in cannabis products that are self-selected by study participants. Unfortunately, blinded, placebo-controlled clinical trials evaluating the efficacy of cannabis, either alone or as an adjunct therapy for acute opioid withdrawal, are lacking. This is not entirely surprising, given cannabis' status as a Schedule I substance in the 
United States, which precludes federal funding to investigate cannabis as a medication-assisted therapy.

Unlike whole-plant cannabis, dronabinol, an FDAapproved analog of THC, has been evaluated for opioid withdrawal relief in a placebo-controlled study in patients receiving the opioid antagonist naltrexone. Lowdose adjunct dronabinol improved the tolerability of symptoms such as insomnia, reduced appetite, and reduced energy levels during opioid detoxification, whereas adverse events such as tachycardia were reported at higher dronabinol doses. ${ }^{13,116,117}$ In many studies, cannabinoids were safe and tolerable when coadministered with an opioid or opioid replacement medication. ${ }^{47,113,118-120}$ However, the comparative efficacy of dronabinol or other cannabinoids versus traditional replacement therapies such as methadone or buprenorphine remains to be elucidated. Given the efficacy and tolerability of Sativex (a whole-plant cannabis derivative) for pain and spasticity, investigation of adjunct Sativex for opioid withdrawal is warranted. ${ }^{121-123}$

Like opioids, chronic cannabis exposure induces the development of tolerance, physical dependence, and withdrawal symptoms during abstinence. Patients commonly report that cannabis withdrawal symptoms, most commonly anger, aggression, irritability, anxiety, decreased appetite, weight loss, restlessness, and sleeping difficulties, ${ }^{124-129}$ are similar to those produced by nicotine withdrawal. ${ }^{129}$ Comparatively, the magnitude and severity of cannabis withdrawal are significantly and substantially more benign than opioid withdrawal. ${ }^{20,126}$ In addition, and unlike opioids, cannabinoid withdrawal and subsequent relapse are nonlethal after periods of abstinence. The reduced intensity of cannabinoid withdrawal symptoms compared to opioids could at least partially be explained by the prolonged period of metabolization of cannabinoids in the body, ${ }^{102}$ contributing to the mounting support for cannabis as a harm-reduction tool to combat OUD.

\section{Cannabis as a Harm Reduction Tool in OUD}

Pre-clinical evidence suggests that the $\mathrm{CB} 1$ receptor plays a critical role in opioid reward. Cannabinoid antagonism reduces the rewarding properties of opioids and prevents reinstatement of drug seeking. ${ }^{105,130,131}$ However, these effects were not reproducible in human clinical trials. ${ }^{132-134}$ Unlike CB1 antagonism, $\mathrm{CB} 1$ agonism may play a role in OUD treatment. Several studies have shown that adjunct cannabis decreases opioid consumption or prevents opioid dose escalation. ${ }^{37-42,121,135}$ Although these findings are promising, several other studies have shown that cannabis use either has no impact on opioid consumption or may increase nonmedical opioid use. ${ }^{136-138}$

The mechanisms underlying cannabis alteration of opioid consumption are yet to be determined; however, there is significant pre-clinical evidence which suggests that $\mathrm{CBD}$, one of the most prevalent cannabinoid molecules in cannabis, plays a critical role. CBD does not have reinforcing effects in rodents, which supports its low potential for misuse. ${ }^{16,139} \mathrm{CBD}$ has been shown to reduce the rewarding aspects of multiple drugs of abuse, such as cocaine, amphetamine, ${ }^{16}$ and nicotine. ${ }^{140}$ Administration of CBD also attenuates morphine $\mathrm{CPP}$ and cue-induced reinstatement of heroin self-administration in rats, without creating any aversive or rewarding effects on its own. ${ }^{106,141-143}$

These findings provide promising rationale for the use of CBD in opioid relapse prevention in humans. In fact, pilot clinical studies have shown that in individuals recently abstinent from heroin, CBD reduces heroin craving. ${ }^{142}$ This effect occurs as soon as $1 \mathrm{~h}$ after administration and lasts for up to 7 days. Adjunct CBD appears to be safe and tolerable, as 400 and $800 \mathrm{mg}$ oral CBD administration does not intensify the effects of intravenous fentanyl or create any adverse effects. ${ }^{118}$ Because CBD is neither intoxicating nor rewarding and has an extremely large therapeutic window and impressive safety profile, the use of CBD to inhibit opioid craving has great therapeutic potential.

Adjunct cannabis use alongside current treatment strategies could help to improve the number of individuals engaging in OUD treatment, as well as increase treatment retention rates. Both dronabinol and intermittent whole-plant cannabis appear to increase the length of time patients remain in treatment for OUD. ${ }^{6,113}$ However, chronic cannabis consumption during naltrexone treatment was ineffective at improving treatment retention, highlighting the need for further research into the dose and frequency of cannabis use in OUD treatment retention and relapse prevention. ${ }^{144}$ Although the ubiquitous and ever-growing regulated cannabis markets across North America could potentially address the aforementioned shortcomings in OUD treatment accessibility and retention, there are currently very few addiction and recovery centers that have embraced concurrent social support and cannabis-assisted OUD treatment. ${ }^{51}$ This is unsurprising given the lack of empirical evidence to support this approach, and the lack of federal research funding that would support this work.

In addition to the clinical and experimental observations outlined above, epidemiological investigations in 
U.S. states with legal cannabis have provided insight into the promising role for cannabis in the opioid crisis. The implementation of both medical and adult-use cannabis laws appears to have a significant impact on opioid consumption and overdose. These states experience a $23 \%$ reduction in nonfatal opioid overdoses, as measured at hospital emergency departments. ${ }^{145}$ By analyzing death certificates, Bachhuber et al. found a $24 \%$ reduction in the annual rate of fatal opioid overdoses in the first year following medical cannabis legalization, ${ }^{146}$ an effect that gets larger the longer a state has had legal cannabis $33 \%$ in California, which has had medical use since 1996 and the lowest rate of opioid overdose fatalities in the country). ${ }^{146,147}$ This finding was also seen in data from the FARS, which demonstrates a similar drop in mortalities of opioid positive automobile accidents in states with implemented cannabis legalization for individuals aged $21-40 .{ }^{148}$ The mechanisms underlying cannabis' ability to reduce opioid hospitalization and mortality are unclear; however, analysis of the Medicare Part D prescription drug program has unveiled the possibility that cannabis may be serving as an analgesic alternative to opioids for individuals living in these states. ${ }^{149}$ The number of filled POAs is substantially lower in states with the most liberal cannabis laws, where there are 3.742 million fewer daily doses than in states with the most prohibitive laws. ${ }^{150}$

These epidemiological impacts are not exclusive to opioid prescriptions, hospitalizations, and mortality; the U.S. economy could also benefit from expanded cannabis legalization. Opioids cost patients and insurance companies upwards of 2.6 billion dollars in healthcare costs annually. ${ }^{151}$ While cannabis is still federally illegal, and in most cases dispensary purchases are not eligible to be covered under any healthcare insurance plan, states with legalized cannabis have seen significant decreases in Medicare Part D prescription drug spending, including, but not limited to, prescription opioids. ${ }^{149,152-155}$ Reductions in spending from Medicare Part D were over $\$ 165$ million dollars. ${ }^{149}$ If cannabis were removed from Schedule I of the Controlled Substance Act and more patients had access to cannabis, savings from pharmaceutical costs incurred by the Medicare Part D prescription plan are projected to continue to climb. ${ }^{149}$

\section{Shortcomings of Cannabis} in Medication-Assisted Therapy

Although the literature thoroughly supports the safety and tolerability of cannabis, ${ }^{38,118,142,156}$ there is con- flicting evidence for its efficacy as a treatment for opioid misuse. Throughout the history of methadone administration, patients have reported that cannabis provides relief from opioid withdrawal symptoms, as well as breakthrough pain and anxiety. ${ }^{119}$ However, other evidence demonstrates that cannabis does not relieve withdrawal symptoms for individuals undergoing methadone tapering, and some participants even reported increased severity of their withdrawal symptoms. ${ }^{104}$ All the participants in the latter study procured their own cannabis and reported smoking as the route of administration. Because the dose of cannabinoids and phytochemical makeup of wholeplant cannabis have significant impacts on physiological responses (such as tachycardia) and subjective experiences (such as anxiety), additional research is needed to characterize maximally efficacious treatment protocols. ${ }^{116,157}$ When used to treat opioid withdrawal symptoms, undesirable side effects also occur in a dose-dependent manner for the FDA-approved cannabinoid dronabinol. ${ }^{113}$ The homogenous and consistent formulation of this pharmaceutical combined with the logistical ease of prescribing the drug may make it more feasible than whole-plant cannabis for clinical trials on cannabinoid alleviation of opioid withdrawal symptoms and relapse prevention.

Despite the promising results of reducing or maintaining a consistent opioid dose, it is plausible that the substitution of one rewarding substance (opioids) for another (THC) could be problematic, leading to cannabis use disorder (CUD). In 2016, 1.4-2.9\% of adults over the age of 18 in the United States met criteria for CUD. ${ }^{79}$ With revisions to the criteria of substance use disorders in 2013, 19\% of individuals who use cannabis throughout their lifetime would eventually meet the Diagnostic and Statistical Manual of Mental Disorders, Fifth Edition (DSM-5) criteria for CUD. ${ }^{153}$ The interpersonal or employment hardships experienced by these individuals that resulted in the meeting of DSM criteria may have simply been due to the legality of cannabis use; that is, a false CUD diagnosis is less likely to occur in the postprohibition era, when patients are no longer breaking the law.

Risks of CUD seem to be correlated with higher THC concentrations, ${ }^{153}$ which is a valid concern in legal markets where average THC potency is upward of $20 \% .{ }^{158}$ Recreational users of cannabis have historically consumed cultivars higher in THC and lower in CBD, due to the desired intoxicating effects of THC. ${ }^{38}$ Medical users, however, have turned to cultivars higher in 
CBD and lower in THC in an attempt to optimize the medicinal benefits of cannabis. ${ }^{38,153}$ Although misuse potential is a valid concern, it is notable that the misuse liability of cannabis is very low. ${ }^{159}$ One possible approach to alleviate the concern of misuse is the concurrent administration of opioid antagonists. This approach seems to reduce the rewarding properties, but not the hyperphagia or withdrawal-relieving properties of THC. ${ }^{160-164}$ These data suggest that combined cannabis and opioid-antagonist therapy could be an effective tool against OUD, while also minimizing the risk for CUD. Because cannabis does not carry the risk of fatal overdose, the use of cannabis as a harmreduction treatment in the opioid epidemic warrants further investigation.

\section{Summary and Future Directions}

The opioid overdose epidemic is arguably the worst public health crisis in U.S. history. At the time of this publication, more people are dying than at the peak of the AIDS epidemic, and for the first time, drug overdoses outnumber automobile and handgun deaths. ${ }^{165}$ A continental crisis of this magnitude warrants the immediate implementation of novel strategies that prevent opioid misuse, overdose, and death.

Growing pre-clinical and clinical evidence appears to support the use of cannabis for these purposes. The evidence summarized in this article demonstrates the potential cannabis has to ease opioid withdrawal symptoms, reduce opioid consumption, ameliorate opioid cravings, prevent opioid relapse, improve OUD treatment retention, and reduce overdose deaths. Cannabis' greatest potential to positively impact the opioid epidemic may be due to its promising role as a first line analgesic in lieu of or in addition to opioids. The comparative efficacy of cannabis alone or in conjunction with current medication-assisted OUD therapies is not well characterized. However, no other intervention, policy, pharmacotherapy, or treatment paradigm has been as impactful as cannabis legislation has been on the rates of opioid consumption, overdose, and death.

Many of the barriers that prevent people from accessing traditional OUD treatment do not apply to cannabis therapy, and access to cannabis medicine is rapidly growing as more U.S. states roll back prohibition. However, a major barrier in universal patient access and improvement in the opioid epidemic is cannabis' status as a Schedule I controlled substance. ${ }^{166}$

Undoubtedly, more high-quality clinical evidence is needed to further support the use of cannabis to combat
OUD; however, federal grant funding that would support these types of clinical trials is currently outside the scope of interest of the National Institutes of Health (because of Schedule I, cannabis is federally considered to have no medical benefit). Patients, healthcare providers, and regulating bodies would all greatly benefit from additional evidence that fills in massive gaps in the knowledge base about the utility of cannabis for OUD treatment: dosing, cannabinoid content and ratios, bioavailability, contraindications, misuse liability, route of administration, and many other questions remain. Even the clinical work that has been conducted thus far may have little validity in the modern landscape of legalized cannabis; all federally-funded cannabis research in the United States is conducted using a single source of cannabis (NIDA drug supply), which is notoriously low in potency and quality, and does not resemble the staggering phytochemical variability in whole-plant cannabis products in regulated state markets. ${ }^{36}$ These barriers to research funding and access to "real world" cannabis for clinical research directly contribute to our inability to address the opioid epidemic with what appears to be a safe and efficacious tool.

In light of the evidence presented in this article, and despite a lack of FDA approval, some U.S. states and private treatment centers have already begun to include cannabis as a part of OUD treatment protocols. The state of New Jersey recently added OUD to their list of qualifying conditions for participation in the state's medical cannabis program. ${ }^{167,168}$ Some private treatment centers are also citing the benefits of harm reduction, which greatly outweigh the risks of cannabis use during the first 28 days of recovery, a critical time period for patient survival. ${ }^{76}$

Many clinicians remain skeptical of cannabis as a viable treatment option, either due to the stigma surrounding cannabis use or the belief that there is not enough clinical evidence for them to feel confident providing patients with cannabis recommendations. ${ }^{169}$ This is unsurprising, given that $85 \%$ of recent medical school graduates still receive no education whatsoever about cannabis throughout their training, residencies, or fellowships. ${ }^{170}$ As the evidence in this field accumulates, it will be critically important to widen opportunities for clinicians to participate in Continuing Medical Education programs, which include the harm reduction and medical benefits that cannabis could provide. Evidencebased opioid prescription and cannabis recommendation practices are a critical component of continuing education, so that clinicians can continue to uphold their Hippocratic oaths to "do no harm." 


\section{Acknowledgment}

Supported by grant funding from the National Institute on Drug Abuse to A.W.-P. (K99DA041467).

\section{Author Disclosure Statement \\ No competing financial interests exist.}

\section{References}

1. Control CfD. Centers for Disease Control and Prevention Understanding the Epidemic 2017. Available at: https://www.cdc.gov/drugoverdose/ epidemic (accessed October 12, 2017).

2. DuPont RL. The opioid epidemic is an historic opportunity to improve both prevention and treatment. Brain Res Bull. 2018;138:112-114.

3. Seth P, Scholl L, Rudd RA, et al. Overdose deaths involving opioids, cocaine, and psychostimulants-United States, 2015-2016. MMWR Morb Mortal Wkly Rep. 2018;67:349-358.

4. National Academies of Sciences, Engineering, and Medicine. Pain management and the opioid epidemic: balancing societal and individual benefits and risks of prescription opioid use. National Academies Press: Washington, DC, 2017.

5. Blum K, Gold MS, Jacobs W, et al. Neurogenetics of acute and chronic opiate/opioid abstinence: treating symptoms and the cause. Front Biosc (Landmark Ed). 2017;22:1247-1288.

6. Scavone JL, Sterling RC, Van Bockstaele EJ. Cannabinoid and opioid interactions: implications for opiate dependence and withdrawal. Neuroscience. 2013;248:637-654

7. Rudd RA, Aleshire N, Zibbell JE, et al. Increases in drug and opioid overdose deaths-United States, 2000-2014. Am J Transplant. 2016;16: 1323-1327.

8. Cicero TJ, Ellis MS, Surratt $\mathrm{HL}$, et al. The changing face of heroin use in the United States: a retrospective analysis of the past 50 years. JAMA Psychiatry. 2014;71:821-826.

9. Yarmolinsky A, Rettig RA. Federal regulation of methadone treatment. National Academies Press: Washington, DC, 1995.

10. Substance Abuse and Mental Health Services Administration. Medication-assisted treatment for substance use disorders: Division of Pharmacologic Therapies. Available at: https://dpt2.samhsa.gov/ treatment/directory.aspx (accessed October 12, 2017).

11. Huhn AS, Tompkins DA, Dunn KE. The relationship between treatment accessibility and preference amongst out-of-treatment individuals who engage in non-medical prescription opioid use. Drug Alcohol Depend. 2017;180:279-285

12. Wallace MJ, Wiley JL, Martin BR, et al. Assessment of the role of CB1 receptors in cannabinoid anticonvulsant effects. Eur J Pharmacol. 2001; 428:51-57.

13. Cicero TJ, Ellis MS, Harney J. Shifting patterns of prescription opioid and heroin abuse in the United States. N Engl J Med. 2015;373:17891790.

14. Centers for Disease Control and Prevention. Increase in overdose deaths involving synthetic opioids other than methadone linked to increase in supply of fentanyl in PBSS states. 2017. Available at: https:// www.cdc.gov/drugoverdose/pdf/pbss/PBSS-Report-072017.pdf (accessed October 12, 2017).

15. Wolff RF, Aune D, Truyers C, et al. Systematic review of efficacy and safety of buprenorphine versus fentanyl or morphine in patients with chronic moderate to severe pain. Curr Med Res Opin. 2012;28:833-845.

16. Parker LA, Burton P, Sorge RE, et al. Effect of low doses of $\Delta 9$ tetrahydrocannabinol and cannabidiol on the extinction of cocaineinduced and amphetamine-induced conditioned place preference learning in rats. Psychopharmacology (Berl). 2004;175:360-366.

17. Wilson-Poe AR, Pocius $E$, Herschbach $M$, et al. The periaqueductal gray contributes to bidirectional enhancement of antinociception between morphine and cannabinoids. Pharmacol Biochem Behav. 2013;103:444-449.

18. Gossop M, Battersby M, Strang J. Self-detoxification by opiate addicts: a preliminary investigation. Br J Psychiatry. 1991;159:208-212.

19. Scavone JL, Mackie K, Van Bockstaele EJ. Characterization of cannabinoid1 receptors in the locus coeruleus: relationship with mu-opioid receptors. Brain Res. 2010;1312:18-31.
20. López-Moreno JA, López-Jiménez A, Gorriti MA, et al. Functional interactions between endogenous cannabinoid and opioid systems: focus on alcohol, genetics and drug-addicted behaviors. Curr Drug Targets. 2010; 11:406-428.

21. Wills $\mathrm{KL}$, DeVuono $\mathrm{MV}$, Limebeer $\mathrm{CL}$, et al. $\mathrm{CB}_{1}$ receptor antagonism in the bed nucleus of the stria terminalis interferes with affective opioid withdrawal in rats. Behav Neurosci. 2017;131:304-311.

22. Parolaro D, Rubino T, Viganò $D$, et al. Cellular mechanisms underlying the interaction between cannabinoid and opioid system. Curr Drug Targets. 2010;11:393-405.

23. Wilson-Poe AR, Morgan MM, Aicher SA, et al. Distribution of CB1 cannabinoid receptors and their relationship with mu-opioid receptors in the rat periaqueductal gray. Neuroscience. 2012;213:191-200.

24. Ahmad T, Lauzon NM, de Jaeger $X$, et al. Cannabinoid transmission in the prelimbic cortex bidirectionally controls opiate reward and aversion signaling through dissociable kappa versus $\mu$-opiate receptor dependent mechanisms. J Neurosci. 2013;33:15642-15651.

25. Braida $D$, losuè $S$, Pegorini $S$, et al. $\Delta 9$-Tetrahydrocannabinol-induced conditioned place preference and intracerebroventricular selfadministration in rats. Eur J Pharmacol. 2004;506:63-69.

26. Singh ME, Verty AN, McGregor IS, et al. A cannabinoid receptor antag onist attenuates conditioned place preference but not behavioural sensitization to morphine. Brain Res. 2004;1026:244-253.

27. Wills KL, Parker LA. Effect of pharmacological modulation of the endocannabinoid system on opiate withdrawal: a review of the preclinical animal literature. Front Pharmacol. 2016;7:187.

28. Yamaguchi T, Hagiwara Y, Tanaka H, et al. Endogenous cannabinoid, 2arachidonoylglycerol, attenuates naloxone-precipitated withdrawal signs in morphine-dependent mice. Brain Res. 2001;909:121-126.

29. Sagheddu C, Muntoni AL, Pistis M, et al. Endocannabinoid signaling in motivation, reward, and addiction: influences on mesocorticolimbic dopamine function. Int Rev Neurobiol. 2015;125:257-302.

30. Befort K. Interactions of the opioid and cannabinoid systems in reward: insights from knockout studies. Front Pharmacol. 2015;6:6.

31. Martin M, Ledent C, Parmentier M, et al. Cocaine, but not morphine, induces conditioned place preference and sensitization to locomotor responses in CB1 knockout mice. Eur J Neurosci. 2000;12:4038-4046.

32. Rice OV, Gordon N, Gifford AN. Conditioned place preference to morphine in cannabinoid CB1 receptor knockout mice. Brain Res. 2002;945:135-138.

33. Lichtman $\mathrm{AH}$, Sheikh SM, Loh $\mathrm{HH}$, et al. Opioid and cannabinoid modulation of precipitated withdrawal in $\Delta$ 9-tetrahydrocannabinol and morphine-dependent mice. J Pharmacol Exp Ther. 2001;298:1007-1014.

34. Valverde $\mathrm{O}$, Noble $\mathrm{F}$, Beslot $\mathrm{F}$, et al. $\Delta$ 9-tetrahydrocannabinol releases and facilitates the effects of endogenous enkephalins: reduction in morphine withdrawal syndrome without change in rewarding effect. Eur J Neurosci. 2001;13:1816-1824.

35. Massaly N, Morón JA, Al-Hasani R. A trigger for opioid misuse: chronic pain and stress dysregulate the mesolimbic pathway and kappa opioid system. Front Neurosci. 2016;10:480.

36. National Academies of Sciences, Engineering, and Medicine. The health effects of cannabis and cannabinoids: the current state of evidence and recommendations for research. National Academies Press: Washington, DC, 2017.

37. Boehnke KF, Litinas E, Clauw DJ. Medical cannabis use is associated with decreased opiate medication use in a retrospective cross-sectional survey of patients with chronic pain. J Pain. 2016;17:739-744.

38. Gruber SA, Sagar KA, Dahlgren MK, et al. Splendor in the grass? A pilot study assessing the impact of medical marijuana on executive function. Front Pharmacol. 2016;7:355.

39. Haroutounian S, Ratz Y, Ginosar Y, et al. The effect of medicinal cannabis on pain and quality-of-life outcomes in chronic pain: a prospective open-label study. Clin J Pain. 2016;32:1036-1043.

40. Kral AH, Wenger L, Novak SP, et al. Is cannabis use associated with less opioid use among people who inject drugs? Drug Alcohol Depend. 2015;153:236-241.

41. Reiman A, Welty M, Solomon P. Cannabis as a substitute for opioidbased pain medication: patient self-report. Cannabis Cannabinoid Res. 2017;2:160-166.

42. Bellnier T, Brown GW, Ortega TR. Preliminary evaluation of the efficacy, safety, and costs associated with the treatment of chronic pain with medical cannabis. Ment Health Clin. 2018;8:110-115. 
43. Stith SS, Vigil JM, Adams IM, et al. Effects of legal access to cannabis on scheduled II-V drug prescriptions. J Am Med Dir Assoc. 2018;19:59-64.e1.

44. Cichewicz DL, McCarthy EA. Antinociceptive synergy between $\Delta 9$ tetrahydrocannabinol and opioids after oral administration. J Pharmacol Exp Ther. 2003;304:1010-1015.

45. Kazantzis NP, Casey SL, Seow PW, et al. Opioid and cannabinoid synergy in a mouse neuropathic pain model. Br J Pharmacol. 2016;173:2521-2531.

46. Phillips TJ, Cherry CL, Cox S, et al. Pharmacological treatment of painful HIV-associated sensory neuropathy: a systematic review and metaanalysis of randomised controlled trials. PLoS One. 2010;5:e14433.

47. Roberts JD, Gennings C, Shih M. Synergistic affective analgesic interaction between delta-9-tetrahydrocannabinol and morphine. Eur J Pharmacol. 2006;530:54-58

48. Abrams DI, Couey P, Shade SB, et al. Cannabinoid-opioid interaction in chronic pain. Clin Pharmacol Ther. 2011;90:844-851.

49. Wilson AR, Maher $L$, Morgan MM. Repeated cannabinoid injections into the rat periaqueductal gray enhance subsequent morphine antinociception. Neuropharmacology. 2008;55:1219-1225.

50. Smith PA, Selley DE, Sim-Selley LJ, et al. Low dose combination of morphine and delta9-tetrahydrocannabinol circumvents antinociceptive tolerance and apparent desensitization of receptors. Eur J Pharmacol. 2007;571:129-137.

51. Lucas P, Walsh Z. Medical cannabis access, use, and substitution for prescription opioids and other substances: a survey of authorized medical cannabis patients. Int J Drug Policy. 2017;42:30-35.

52. Reiman A. Cannabis as a substitute for alcohol and other drugs. Harm Reduc J. 2009:6:35.

53. Finn DP, Jhaveri MD, Beckett SR, et al. Effects of direct periaqueductal grey administration of a cannabinoid receptor agonist on nociceptive and aversive responses in rats. Neuropharmacology. 2003;45:594-604.

54. Jensen TS, Yaksh TL. Comparison of antinociceptive action of morphine in the periaqueductal gray, medial and paramedial medulla in rat. Brain Res. 1986;363:99-113.

55. Varvel SA, Bridgen DT, Tao Q, et al. Delta9-tetrahydrocannbinol accounts for the antinociceptive, hypothermic, and cataleptic effects of marijuana in mice. J Pharmacol Exp Ther. 2005;314:329-337.

56. Cooper ZD, Bedi G, Ramesh D, et al. Impact of co-administration of oxycodone and smoked cannabis on analgesia and abuse liability. Neuropsychopharmacology. 2018. [Epub ahead of print]; DOI: 10.1038/ s41386-018-0011-2

57. Li JX, McMahon LR, Gerak LR, et al. Interactions between delta (9)tetrahydrocannabinol and mu opioid receptor agonists in rhesus monkeys: discrimination and antinociception. Psychopharmacology (Berl). 2008;199:199-208.

58. Christie MJ, Connor M, Vaughan CW, et al. Cellular actions of opioids and other analgesics: implications for synergism in pain relief. Clin Exp Pharmacol Physiol. 2000;27:520-523.

59. Fields $\mathrm{HL}$, Heinricher MM. Anatomy and physiology of a nociceptive modulatory system. Philos Trans R Soc Lond B Biol Sci. 1985;308:361-374.

60. Fyfe LW, Cleary DR, Macey TA, et al. Tolerance to the antinociceptive effect of morphine in the absence of short-term presynaptic desensitization in rat periaqueductal gray neurons. J Pharmacol Exp Ther. 2010; 335:674-680.

61. Heinricher MM, Ingram SL. The Brainstem and Nociceptive Modulation In: Bushnell MC, Basbaum Al, eds. The Senses: A Comprehensive Reference 5.41. Academic Press: Cambridge MA, 2008, pp. 593-626

62. Wilson-Poe AR, Mitchell VA, Vaughan CW. Postsynaptic mGluR mediated excitation of neurons in midbrain periaqueductal grey. Neuropharmacology. 2013;66:348-354.

63. Kampman K, Jarvis M. American Society of Addiction Medicine (ASAM) national practice guideline for the use of medications in the treatment of addiction involving opioid use. J Addict Med. 2015;9:358-367.

64. Rehni AK, Jaggi AS, Singh N. Opioid withdrawal syndrome: emerging concepts and novel therapeutic targets. CNS Neurol Disord Drug Targets. 2013;12:112-125.

65. Calabria B, Degenhardt L, Briegleb C, et al. Systematic review of prospective studies investigating "remission" from amphetamine, cannabis, cocaine or opioid dependence. Addict Behav. 2010;35:741-749.

66. Ramsey SE, Rounsaville D, Hoskinson R, et al. The need for psychosocial interventions to facilitate the transition to extended-release naltrexone (XR-NTX) treatment for opioid dependence: a concise review of the literature. Subst Abuse. 2016;10:65-68.
67. Bart G. Maintenance medication for opiate addiction: the foundation of recovery. J Addict Dis. 2012;31:207-225.

68. Center for Substance Abuse Treatment. Medication-assisted treatment for opioid addiction in opioid treatment programs. Substance Abuse and Mental Health Services Administration: Rockville, MD, 2005.

69. Connery HS. Medication-assisted treatment of opioid use disorder: review of the evidence and future directions. Harv Rev Psychiatry. 2015;23: 63-75.

70. Fullerton CA, Kim M, Thomas CP, et al. Medication-assisted treatment with methadone: assessing the evidence. Psychiatr Serv. 2014;65:146-157.

71. Gorodetzky CW, Walsh SL, Martin PR, et al. A phase III, randomized, multi-center, double blind, placebo controlled study of safety and efficacy of lofexidine for relief of symptoms in individuals undergoing inpatient opioid withdrawal. Drug Alcohol Depend. 2017;176: 79-88.

72. Schuckit MA. Treatment of opioid-use disorders. N Engl J Med. 2016;375: 357-368.

73. Novick DM, Salsitz EA, Joseph $\mathrm{H}$, et al. Methadone medical maintenance: an early 21st-century perspective. J Addict Dis. 2015;34:226-237.

74. Connock M, Juarez-Garcia A, Jowett $S$, et al. Methadone and buprenorphine for the management of opioid dependence: a systematic review and economic evaluation. Health Technol Assess. 2007;11:1-171, iii-iv.

75. Kreek MJ. Medical safety and side effects of methadone in tolerant individuals. JAMA. 1973;223:665-668.

76. Reed K, Day E, Keen J, et al. Pharmacological treatments for drug misuse and dependence. Expert Opin Pharmacother. 2015;16:325-333.

77. Kimber J, Larney S, Hickman M, et al. Mortality risk of opioid substitution therapy with methadone versus buprenorphine: a retrospective cohort study. Lancet Psychiatry. 2015;2:901-908.

78. Kosten TR, O'Connor PG. Management of drug and alcohol withdrawal. N Engl J Med. 2003;348:1786-1795.

79. Services USDOHaH. Substance Abuse and Mental Health Services Administration Detoxification and substance abuse treatment. 2017, p. 49. Available at: https://store.samhsa.gov/shin/content/SMA15-4131/ SMA15-4131.pdf (accessed March 18, 2018).

80. Stein BD, Pacula RL, Gordon AJ, et al. Where is buprenorphine dispensed to treat opioid use disorders? The role of private offices, opioid treatment programs, and substance abuse treatment facilities in urban and rural counties. Milbank Q. 2015;93:561-583.

81. Fisher GL, Roget NA. Encyclopedia of substance abuse prevention, treatment, and recovery. Sage: Thousand Oaks, CA, 2009.

82. Rosen K, Gutierrez A, Haller D, et al. Sublingual buprenorphine for chronic pain: a survey of clinician prescribing practices. Clin J Pain. 2014 30:295-300.

83. Jones JD, Manubay JM, Mogali S, et al. Abuse liability of intravenous buprenorphine vs. buprenorphine/naloxone: importance of absolute naloxone amount. Drug Alcohol Depend. 2017;179:362-369.

84. Alho $H$, Sinclair $D$, Vuori $E$, et al. Abuse liability of buprenorphinenaloxone tablets in untreated IV drug users. Drug Alcohol Depend. 2007, 88:75-78

85. Wesson DR, Ling W. The clinical opiate withdrawal scale (COWS). J Psychoact Drugs. 2003;35:253-259.

86. Urnoski E. Why is buprenorphine coformulated with naloxone? JAAPA. 2017;30:44-45.

87. Wiegand TJ, Le Lait MC, Bartelson BB, et al. Analysis of the abuse and diversion of the buprenorphine transdermal delivery system. J Pain. 2016;17:745-752.

88. Rosenblatt RA, Andrilla CHA, Catlin M, et al. Geographic and specialty distribution of US physicians trained to treat opioid use disorder. Ann Fam Med. 2015;13:23-26.

89. Sansone RA, Sansone LA. Buprenorphine treatment for narcotic addiction: not without risks. Innov Clin Neurosci. 2015;12:32-36.

90. Dick AW, Pacula RL, Gordon AJ, et al. Growth in buprenorphine waivers for physicians increased potential access to opioid agonist treatment, 2002-11. Health Aff (Millwood). 2015;34:1028-1034.

91. Hutchinson $E$, Catlin $M$, Andrilla $\mathrm{CHA}$, et al. Barriers to primary care physicians prescribing buprenorphine. Ann Fam Med. 2014;12: 128-133.

92. Kakko J, Svanborg KD, Kreek MJ, et al. 1-year retention and social function after buprenorphine-assisted relapse prevention treatment for heroin dependence in Sweden: a randomised, placebo-controlled trial. Lancet. 2003;361:662-668. 
93. Hser YI, Saxon AJ, Huang D, et al. Treatment retention among patients randomized to buprenorphine/naloxone compared to methadone in a multi-site trial. Addiction. 2014;109:79-87.

94. Copenhaver MM, Bruce RD, Altice FL. Behavioral counseling content for optimizing the use of buprenorphine for treatment of opioid dependence in community-based settings: a review of the empirical evidence. Am J Drug Alcohol Abuse. 2007;33:643-654.

95. Montoya ID, Schroeder JR, Preston KL, et al. Influence of psychotherapy attendance on buprenorphine treatment outcome. J Subst Abuse Treat. 2005;28:247-254.

96. FDA Requirement. Post market drug safety information for patients and providers. Available at: www.fda.gov/downloads/drugs/drugsafety/post marketdrugsafetyinformationforpatientsandpro (accessed January 10, 2017)

97. BupPractice. Physician requirements to prescribe buprenorphine. Clinical Tools, Inc. 2014; Available at: https://www.buppractice.com/node/ 4335 (accessed May 3, 2018).

98. Gowing L, Ali R, White JM. Opioid antagonists with minimal sedation for opioid withdrawal. Cochrane Database Syst Rev. 2017;5: CD002021.

99. Guo S, Manning V, Yang Y, et al. Lofexidine versus diazepam for the treatment of opioid withdrawal syndrome: a double-blind randomized clinical trial in Singapore. J Subst Abuse Treat. 2018;91:1-11.

100. Law FD, Diaper AM, Melichar JK, et al. Buprenorphine/naloxone versus methadone and lofexidine in community stabilisation and detoxification: a randomised controlled trial of low dose short-term opiatedependent individuals. J Psychopharmacol. 2017;31:1046-1055.

101. Deikel SM, Carder B. Attentuation of precipitated abstinence in methadone-dependent rats by delta9-THC. Psychopharmacol Commun 1976;2:61-65.

102. Fattore L, Deiana S, Spano SM, et al. Endocannabinoid system and opioid addiction: behavioural aspects. Pharmacol Biochem Behav. 2005;81: 343-359.

103. Hine B, Torrelio M, Gershon S. Attenuation of precipitated abstinence in methadone-dependent rats by delta 9-THC. Psychopharmacol Commun. 1975; 1:275-283.

104. Epstein $\mathrm{DH}$, Preston KL. No evidence for reduction of opioid-withdrawal symptoms by cannabis smoking during a methadone dose taper. Am J Addict. 2015;24:323-328.

105. Navarro M, Carrera MR, Fratta W, et al. Functional interaction between opioid and cannabinoid receptors in drug self-administration. J Neurosci. 2001:21:5344-5350.

106. de Carvalho CR, Takahashi RN. Cannabidiol disrupts the reconsolidation of contextual drug-associated memories in Wistar rats. Addict Biol. 2017;22:742-751.

107. Izzo AA, Borrelli F, Capasso R, et al. Non-psychotropic plant cannabinoids: new therapeutic opportunities from an ancient herb. Trends Pharmacol Sci. 2009;30:515-527.

108. Thomas A, Baillie GL, Phillips AM, et al. Cannabidiol displays unexpectedly high potency as an antagonist of $C B 1$ and $C B 2$ receptor agonists in vitro. Br J Pharmacol. 2007;150:613-623.

109. Campos AC, Guimarães FS. Evidence for a potential role for TRPV1 receptors in the dorsolateral periaqueductal gray in the attenuation of the anxiolytic effects of cannabinoids. Prog Neuropsychopharmacol Biol Psychiatry. 2009;33:1517-1521.

110. Espejo-Porras F, Fernández-Ruiz J, Pertwee RG, et al. Motor effects of the non-psychotropic phytocannabinoid cannabidiol that are mediated by 5-HT1A receptors. Neuropharmacology. 2013;75:155-163.

111. Seeman P. Cannabidiol is a partial agonist at dopamine D2 high receptors, predicting its antipsychotic clinical dose. Transl Psychiatry. 2016;6:e920.

112. Tham M, Yilmaz O, Alaverdashvili $M$, et al. Allosteric and orthosteric pharmacology of cannabidiol and cannabidiol-dimethylheptyl at the type 1 and type 2 cannabinoid receptors. Br J Pharmacol. 2018.

113. Bisaga A, Sullivan MA, Glass A, et al. The effects of dronabinol during detoxification and the initiation of treatment with extended release naltrexone. Drug Alcohol Depend. 2015;154:38-45.

114. Heikman PK, Muhonen LH, Ojanperä IA. Polydrug abuse among opioid maintenance treatment patients is related to inadequate dose of maintenance treatment medicine. BMC Psychiatry. 2017;17: 245 .
115. Bidwell LC, Mueller R, YorkWilliams SL, et al. A novel observational method for assessing acute responses to cannabis: preliminary validation using legal market strains. Cannabis Cannabinoid Res. 2018;3:35-44.

116. Jicha CJ, Lofwall MR, Nuzzo PA, et al. Safety of oral dronabinol during opioid withdrawal in humans. Drug Alcohol Depend. 2015;157:179-183.

117. Lofwall MR, Babalonis S, Nuzzo PA, et al. Opioid withdrawal suppression efficacy of oral dronabinol in opioid dependent humans. Drug Alcohol Depend. 2016;164:143-150.

118. Manini AF, Yiannoulos G, Bergamaschi MM, et al. Safety and pharmacokinetics of oral cannabidiol when administered concomitantly with intravenous fentanyl in humans. J Addict Med. 2015;9:204-210.

119. Mayet $A$, Lions $C$, Roux $P$, et al. Variations in cannabis use level and correlates in opiate-users on methadone maintenance treatment: a French prospective study. J Subst Abuse Treat. 2015;58:100-105.

120. Naef $M$, Curatolo $M$, Petersen-Felix $S$, et al. The analgesic effect of ora delta-9-tetrahydrocannabinol (THC), morphine, and a THC-morphine combination in healthy subjects under experimental pain conditions. Pain. 2003;105:79-88.

121. Johnson JR, Lossignol D, Burnell-Nugent $M$, et al. An open-label extension study to investigate the long-term safety and tolerability of THC/CBD oromucosal spray and oromucosal THC spray in patients with terminal cancer-related pain refractory to strong opioid analgesics. J Pain Symptom Manag. 2013;46:207-218.

122. MacCallum CA, Russo EB. Practical considerations in medical cannabis administration and dosing. Eur J Intern Med. 2018;49:12-19.

123. Cooper ZD, Comer SD, Haney M. Comparison of the analgesic effects of dronabinol and smoked marijuana in daily marijuana smokers. Neuropsychopharmacology. 2013;38:1984-1992.

124. Budney AJ, Hughes JR. The cannabis withdrawal syndrome. Curr Opin Psychiatry. 2006;19:233-238.

125. Budney AJ, Hughes JR, Moore BA, et al. Review of the validity and significance of cannabis withdrawal syndrome. Am J Psychiatry. 2004;161 1967-1977.

126. Budney AJ, Moore BA, Vandrey RG, et al. The time course and significance of cannabis withdrawal. J Abnorm Psychol. 2003;112:393-402.

127. Levin $\mathrm{KH}$, Copersino ML, Heishman SJ, et al. Cannabis withdrawal symptoms in non-treatment-seeking adult cannabis smokers. Drug Alcohol Depend. 2010;111:120-127.

128. Smith NT. A review of the published literature into cannabis withdrawal symptoms in human users. Addiction. 2002;97:621-632.

129. Allsop DJ, Copeland J, Norberg MM, et al. Quantifying the clinical significance of cannabis withdrawal. PLoS One. 2012;7:e44864.

130. Solinas M, Panlilio LV, Antoniou K, et al. The cannabinoid CB1 antagonist $\mathrm{N}$-piperidinyl-5-(4-chlorophenyl)-1-(2,4-dichlorophenyl)-4methylpyrazole-3-carboxamide (SR-141716A) differentially alters the reinforcing effects of heroin under continuous reinforcement, fixed ratio, and progressive ratio schedules of drug self-administration in rats. J Pharmacol Exp Ther. 2003;306:93-102.

131. Fattore L, Spano M, Melis V, et al. Differential effect of opioid and cannabinoid receptor blockade on heroin-seeking reinstatement and cannabinoid substitution in heroin-abstinent rats. Br J Pharmacol. 2011; 163:1550-1562.

132. Lazary J, Juhasz G, Hunyady L, et al. Personalized medicine can pave the way for the safe use of $\mathrm{CB} 1$ receptor antagonists. Trends Pharmacol Sci. 2011;32:270-280.

133. Thomas KH, Martin RM, Potokar J, et al. Reporting of drug induced depression and fatal and non-fatal suicidal behaviour in the UK from 1998 to 2011. BMC Pharmacol Toxicol. 2014;15:54.

134. Yang $P$, Wang $L$, Xie XQ. Latest advances in novel cannabinoid CB2 ligands for drug abuse and their therapeutic potential. Future Med Chem. 2012:4:187-204.

135. Sam AH, Salem V, Ghatei MA. Rimonabant: from RIO to ban. J Obes. 2011;2011:432607.

136. Degenhardt L, Lintzeris N, Campbell G, et al. Experience of adjunctive cannabis use for chronic non-cancer pain: findings from the Pain and Opioids IN Treatment (POINT) study. Drug Alcohol Depend. 2015; 147:144-150

137. Olfson M, Wall MM, Liu SM, et al. Cannabis use and risk of prescription opioid use disorder in the United States. Am J Psychiatry. 2018;175:4753. 
138. Campbell G, Hall WD, Peacock A, et al. Effect of cannabis use in people with chronic non-cancer pain prescribed opioids: findings from a 4-year prospective cohort study. Lancet Public Health. 2018;3:e341-e350.

139. Katsidoni V, Anagnostou I, Panagis G. Cannabidiol inhibits the rewardfacilitating effect of morphine: involvement of 5-HT1A receptors in the dorsal raphe nucleus. Addict Biol. 2013;18:286-296.

140. Budzyńska B, Kruk M, Biała G. Effects of the cannabinoid CB1 receptor antagonist AM 251 on the reinstatement of nicotine-conditioned place preference by drug priming in rats. Pharmacol Rep. 2009;61:304-310.

141. Markos JR, Harris HM, Gul W, et al. Effects of cannabidiol on morphine conditioned place preference in mice. Planta Med. 2018;84:221-224.

142. Hurd YL, Yoon M, Manini AF, et al. Early phase in the development of cannabidiol as a treatment for addiction: opioid relapse takes initial center stage. Neurotherapeutics. 2015;12:807-815.

143. Ren Y, Whittard J, Higuera-Matas A, et al. Cannabidiol, a nonpsychotropic component of cannabis, inhibits cue-induced heroin seeking and normalizes discrete mesolimbic neuronal disturbances. J Neurosci. 2009; 29:14764-14769.

144. Raby WN, Carpenter KM, Rothenberg J, et al. Intermittent marijuana use is associated with improved retention in naltrexone treatment for opiate-dependence. Am J Addict. 2009;18:301-308.

145. Shi Y. Medical marijuana policies and hospitalizations related to marijuana and opioid pain reliever. Drug Alcohol Depend. 2017;173:144-150.

146. Bachhuber MA, Saloner B, Cunningham CO, et al. Medical cannabis laws and opioid analgesic overdose mortality in the United States, 19992010. JAMA Intern Med. 2014;174:1668-1673.

147. National Institute on Drug Abuse. Opioid overdoses by state drugabuse.gov. National Institutes of Health, 2018; Available at: https:// www.drugabuse.gov/drugs-abuse/opioids/opioid-summaries-by-state/ california-opioid-summary (accessed May 3, 2018).

148. Kim JH, Santaella-Tenorio J, Mauro C, et al. State medical marijuana laws and the prevalence of opioids detected among fatally injured drivers. Am J Public Health. 2016;106:2032-2037.

149. Bradford AC, Bradford WD. Medical marijuana laws reduce prescription medication use in Medicare Part D. Health Aff (Millwood). 2016;35:12301236.

150. Bradford AC, Bradford WD, Abraham A, et al. Association between US state medical cannabis laws and opioid prescribing in the Medicare Part D population. JAMA Intern Med. 2018;178:667-672.

151. Birnbaum HG, White AG, Reynolds JL, et al. Estimated costs of prescription opioid analgesic abuse in the United States in 2001: a societal perspective. Clinical J Pain 2006;22:667-676.

152. Bradford AC, Bradford WD. Factors driving the diffusion of medical marijuana legalisation in the United States. Drugs Educ Prev Policy. 2017;24:75-84.

153. Hasin DS. US Epidemiology of cannabis use and associated problems Neuropsychopharmacology. 2018;43:195-212.

154. Wen $\mathrm{H}$, Hockenberry JM. Association of medical and adult-use marijuana laws with opioid prescribing for Medicaid enrollees. JAMA Intern Med. 2018;178:673-679.

155. Liang $D$, Bao $Y$, Wallace $M$, et al. Medical cannabis legalization and opioid prescriptions: evidence on US Medicaid enrollees during 1993-2014. Addiction. 2018. [Epub ahead of print]; DOI: 10.1111/ add.14382.

156. Robson P. Human studies of cannabinoids and medicinal cannabis. Handb Exp Pharmacol. 2005:719-756.

157. Cuttler C, Spradlin A, McLaughlin RJ. A naturalistic examination of the perceived effects of cannabis on negative affect. J Affect Disord. 2018;235:198-205.

158. Smart R, Caulkins JP, Kilmer B, et al. Variation in cannabis potency and prices in a newly-legal market: evidence from 30 million cannabis sales in Washington State. Addiction. 2017;112:2167-2177.

159. Anthony JC, Warner LA, Kessler RC. Comparative epidemiology of dependence on tobacco, alcohol, controlled substances, and inhalants: basic findings from the National Comorbidity Survey. Exp Clin Psychopharmacol. 1994;2:244-268.

160. Yamamoto T, Takada K. Current perspective-role of cannabinoid receptor in the brain as it relates to drug reward. Jpn J Pharmacol. 2001;84 229-236.

161. Haney M, Ramesh D, Glass A, et al. Naltrexone maintenance decreases cannabis self-administration and subjective effects in daily cannabis smokers. Neuropsychopharmacology. 2015;40:2489-2498.

162. Curran HV, Freeman TP, Mokrysz C, et al. Keep off the grass? Cannabis, cognition and addiction. Nat Rev Neurosci. 2016;17:293-306.

163. Ranganathan M, Carbuto M, Braley G, et al. Naltrexone does not attenuate the effects of intravenous $\Delta 9$-tetrahydrocannabinol in healthy humans. Int J Neuropsychopharmacol. 2012;15:1251-1264.

164. Clasen MM, Flax SM, Hempel BJ, et al. Antagonism of the kappa opioid receptor attenuates THC-induced place aversions in adult male Sprague-Dawley rats. Pharmacol Biochem Behav. 2017;163:30-35.

165. Clark AK, Wilder CM, Winstanley EL. A systematic review of community opioid overdose prevention and naloxone distribution programs. J Addict Med. 2014;8:153-163.

166. Maher DP, Carr DB, Hill K, et al. Cannabis for the treatment of chronic pain in the era of an opioid epidemic: a symposium-based review of sociomedical science. Pain Med. 2017 [Epub ahead of print]; doi: $10.1093 / \mathrm{pm} / \mathrm{pn} \times 143$

167. Department of Health. Medical marijuana program. Department of Health: State of New Jersey, 2018.

168. National Conference of State Legislatures. State medical marijuana laws. 2018. Available at: http://ncsl.org (accessed March 18, 2018).

169. Fitzcharles MA, Eisenberg E. Medical cannabis: a forward vision for the clinician. Eur J Pain. 2018;22:485-491.

170. Evanoff $A B$, Quan T, Dufault $C$, et al. Physicians-in-training are not prepared to prescribe medical marijuana. Drug Alcohol Depend. 2017;180: 151-155.

Cite this article as: Wiese B, Wilson-Poe AR (2018) Emerging

evidence for cannabis' role in opioid use disorder, Cannabis and

Cannabinoid Research 3:1, 179-189, DOI: 10.1089/can.2018.0022.

$\mathrm{BNST}=$ bed nucleus of stria terminalis

$\mathrm{CB} 1=$ cannabinoid 1

$\mathrm{CBD}=$ cannabidiol

$\mathrm{CeA}=$ central amygdala

$\mathrm{CPA}=$ Conditioned Place Aversion

$\mathrm{CPP}=$ conditioned place preference

CUD = cannabis use disorder

DSM = Diagnostic and Statistical Manual of Mental Disorders

FARS $=$ Fatality Analysis Reporting System

$\mathrm{KO}=$ knockout

$\mathrm{KOR}=$ kappa opioid receptor

$\mathrm{MOR}=$ mu opioid receptor

NIDA $=$ National Institute of Drug Abuse

OUD $=$ opioid use disorder

$\mathrm{PFC}=$ prefrontal cortex

POAs $=$ prescription opioid analgesics

$\mathrm{THC}=$ tetrahydrocannabinol

$\mathrm{VTA}=$ ventral tegmental area

\section{Publish in Cannabis and Cannabinoid Research}

Cannabis and

Cannabinoid

Research
- Immediate, unrestricted online access

- Rigorous peer review

- Compliance with open access mandates

- Authors retain copyright

- Highly indexed

- Targeted email marketing 